\title{
Limites e condicionantes à expansão da sojicultura na Amazônia
}

\section{Limits and Constraints to the Expansion of Soybean Production in the Amazon region}

Índio Campos - Mestre em Economia Rural pela Universidade Federal da Paraíba (1987) e doutor em Economia pela Freie Universitat Berlin (1992). Professor/pesquisador do Núcleo de Altos Estudos Amazônicos da Universidade Federal do Pará. E-mail: indio_naea@ufpa.br

\begin{abstract}
Resumo
Tornou-se quase consensual que a expansão do cultivo da soja representa uma grande ameaça à floresta amazônica. Todavia, estas análises carecem de embasamento empírico, podendo inclusive acobertar os verdadeiros "vilões" do desmatamento. Este trabalho analisa a expansão recente da sojicultura no Brasil, sob a lupa da econometria espacial. Dado que os elevados riscos inerentes à cultura da soja recaem exclusivamente sobre aos produtores diretos, em meio a um mercado de grãos estruturado em torno de grandes "tradings" internacionais, constata-se que o cultivo da soja só se viabiliza sob condições ótimas de: solos planos e profundos; clima regular, com regime de chuvas bem definido; infraestrutura de transporte acessível; e financiamento da produção. Condições estas que se resumem a parcas áreas da região amazônica, mormente nas manchas de cerrado. Pecuária e exploração madeireira seguem sendo os grandes responsáveis pelo desmatamento.
\end{abstract}

\section{Palavras-chave}

Econometria espacial. Amazônia. Soja.

\section{Abstract}

It became almost a consensus that the expansion of the soybean production represents a major threat to the Amazon rainforest. However, these analyses lack theoretical support and may contribute to even cover up the real "villains" of the deforestation.This paper analyzes the recent expansion of soybean production in Brazil using the spatial econometrics methodology. Given that the high risks inherent in soybeans production fall exclusively directly on producers in a grain market structured around large international "tradings", it appears that soybean cultivation is only feasible under optimal conditions like: plain and deep soils; climate with regular well defined rainfall, accessible transportation infrastructure, and production financing. Conditions that explain the scarce areas of the Amazon region, located in some savanna areas. Farming and logging are still largely responsible for deforestation.

\section{Keywords}

Spatial econometrics. Amazon rainforest. Soybean. 


\section{INTRODUÇÃO}

A safra brasileira de soja 2010/2011 bateu recordes de produção e produtividade. A Companhia Nacional de Abastecimento (CONAB) aponta a produção de 75 milhões de toneladas, contra 68,7 da safra anterior, o que representa um incremento de 9,6\%. Este aumento é também reflexo da produtividade média recorde, atingindo $3.115 \mathrm{~kg}$ por hectare, ou seja, cerca de 60 sacas. Boa parte destes resultados deve-se ao fator climático, que contribuiu favoravelmente.

Em termos mundiais, a oferta dessa oleaginosa deve atingir 254,84 milhões de toneladas. O consumo previsto para 2011 foi estimado em 252,55 milhões de toneladas, permitindo que os estoques finais mundiais de soja cresçam para 63,61 milhões de toneladas (Figura 1). A China é a maior compradora global da soja. Para sustentar as taxas de crescimento do PIB de $10 \%$ a.a., a china importa de 50 a 55 milhões de toneladas/ano do produto, aproximadamente $1 / 5$ da produção mundial.

A sojicultora já é uma atividade consolidada nos estados do Rio Grande do Sul (RS), Paraná (PR), Santa Catarina (SC), Mato Grosso (MT), Mato Grosso do Sul (MS), Bahia (BA), Minas Gerais (MG), Goiás (GO), Maranhão (MA), Piauí (PI) e Tocantins (TO). Juntos, perfazem $97 \%$ da área cultivada desse agronegócio. Os 3\% restantes são áreas de cerrados nos estados do Pará e Roraima. O sul do estado do Piauí é o grande responsável pela expansão da cultura da soja nos últimos 10 anos. É a chamada de "a última fronteira agrícola do país”, já nos limites do semiárido, nos platôs do Vale Gurgueia.

Figura 1: Produção de soja 1976-2011 no Brasil e Regiões (em 1.000 t).

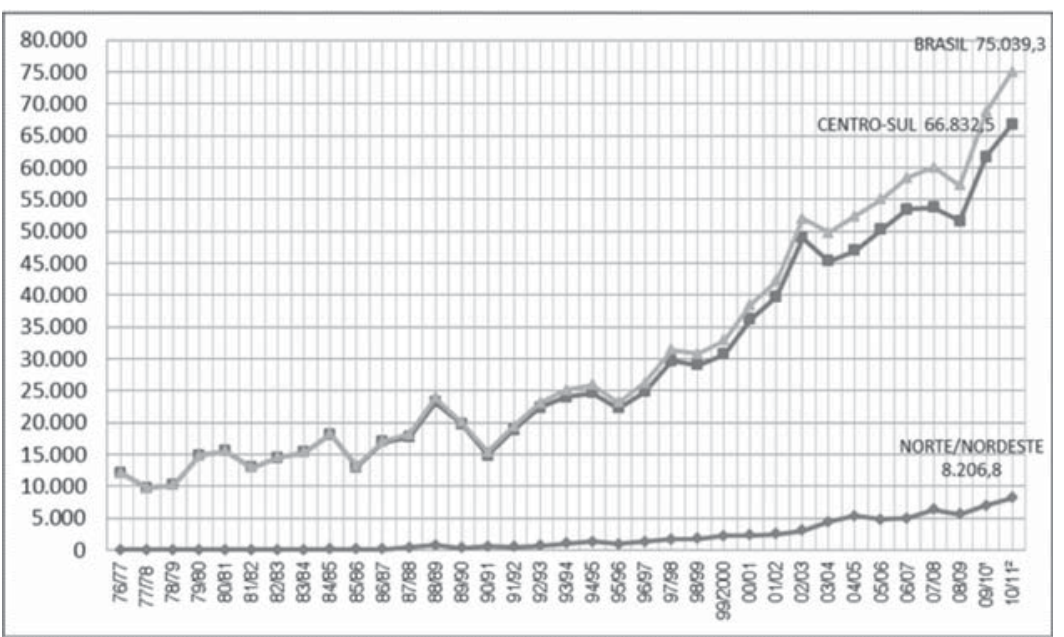

Fonte: CONAB, 2011.

Novos Cadernos NAEA •v. 15 n. $2 \cdot$ p. 197-216 • dez. 2012 
O Brasil tornou-se o segundo maior exportador mundial de soja. A Figura 1 ilustra a série histórica da produção da soja no Brasil para o período de 1976 a 2011. Entre 1976 a 2000, a produção nacional dessa oleaginosa saltou de 12 para 30 milhões de toneladas. Entre 2001 a 2011, a produção de soja cresceu ainda mais rapidamente, elevando-se de 30 para 75 milhões de toneladas, ou seja, duas vezes e meia em uma década.

Em termos espaciais, a região Centro-Sul (composta pelos estados produtores: MT, MS, GO, DF, MG, SP, PR, SC e RS) responde por quase $90 \%$ da produção nacional. O Norte-Nordeste (RR, RO, PA, TO, MA, PI, e BA) complementa o restante. $\mathrm{O}$ avanço da soja sobre a região amazônica preocupa a comunidade científica. Há um temor de que se reproduzam os efeitos negativos do binômio madeireira-pecuária. A soja foi introduzida na região Norte, nos estados de RR e RO, em meados dos anos 1980. Somente em 1997, o estado do Pará principia o cultivo desse grão. Em termos relativos, os estados de RO, RR. MA, PI, TO e BA detêm 96,16\% da produção da região Norte-Nordeste. Assim, o avanço da soja no Pará não apresenta incrementos significativos de produção. Os efeitos climáticos atuantes sobre as regiões Norte e Nordeste impactam fortemente a produção regional de soja. O aquecimento das águas do leste do Oceano Pacífico tropical, fenômeno conhecido como "El Niño", provoca a diminuição dos níveis de precipitação da estação de chuvas na região Nordeste da Amazônia, através da modificação da circulação de Walker (leste-oeste).

Segundo Salazar (2010), “o aquecimento do Atlântico tropical norte em relação com o Atlântico tropical sul desloca para o norte a zona de convergência intertropical devido ao aumento de subsidência sobre a região sul e oeste da Amazônia" (FU et al., 2001), diminuindo suas precipitações na estação seca. Este aquecimento anômalo no norte do Atlântico foi a causa da intensa seca ocorrida na Amazônia no ano de 2005 (MARENGO et al., 2008). Na Figura 2 verifica-se que os estados de RO, PA e MA, apresentaram aumento na produção de soja entre as safras 2004/2005 e 2005/2006, devido à subsidência no período. Em contraposição, os estados de RR, TO, PI e BA foram afetados com a queda entre as safras no período citado, indicando que o efeito do "El Niño" prejudica a produção nessas localidades. De forma espacial, os estados produtores que se encontram próximos ao bioma amazônico são atingidos, diferentemente daqueles que lhe estão distantes.

Perante a enorme heterogeneidade de clima, cobertura vegetal e relevo característicos da região amazônica, o presente trabalho versa sobre a possibilidade de o cultivo de soja efetivamente representar uma nova ameaça à floresta tropical úmida. 


\section{O DEBATE SOBRE A EXPANSÃo DA SOJA NA AMAZÔNIA}

No final do ano de 2003, o Museu Paraense Emílio Goeldi (MPEG) promoveu o seminário "A Geopolítica da Soja na Amazônia”, em parceria com a EMBRAPA. Dele participaram diversos órgãos governamentais: Ministérios da Agricultura (MA) e do Meio Ambiente (MMA), Agência de Desenvolvimento da Amazônia (ADA), Instituto Nacional de Pesquisas da Amazônia (INPA), Instituto Nacional de Pesquisas Espaciais (INPE) e outras; e não governamentais: Movimentos Sociais da Transamazônica, Amigos da Terra e outras. Estavam em pauta os impactos econômicos e ecológicos associados à expansão da sojana Amazônia (VIEIRA, 2004).

Bertha Becker (UFRJ) destacou que ao tratar a soja na região como uma questão geopolítica, um cenário de guerra foi formado, pois

[...] quaisquer relações econômicas no território devem ser vistas como uma guerra. Estamos diante de uma ou várias corporações, e a corporação é um agente extremamente poderoso de reorganização do espaço, envolvendo crescente multifuncionalidade [...], múltiplas localizações em diferentes escalas geográficas. (VIEIRA, 2004).

Charles Roland Clement prossegue:

Já que estamos falando de geopolítica, a ausência de investimento é também uma política, e isto precisa ser dito com muita clareza. E o Brasil tem que decidir se a Amazônia merece o investimento para manter boa parte da floresta de pé, ou deixará essa oportunidade passar para plantar soja e outras coisas similares.

Alfredo Homma (EMBRAPA Amazônia Oriental) salientou que;

[...] temos que chamar a atenção séria, já que o pessoal da soja não desmata mais; ele vai comprar áreas de pequenos produtores, de pastagem degradada; isto tende a empurrar a fronteira agrícola para mais adiante. Esse é um risco que fica embutido atrás da questão dessa expansão da soja $[\ldots]$

Ainda acerca do avanço da soja sobre a Amazônia, Araújo et al. (2008) constataram que:

Certamente que a área de influência da BR-163, do lado paraense, tem sua importância destacada por se constituir uma área de expansão da fronteira da soja, no movimento do Mato Grosso em direção à Calha Norte do Rio Amazonas [...]. Ainda que a produção do Pará seja inexpressiva, comparativamente, o avanço da produção de grãos constitui uma expectativa para grandes empresas que apostam com grossos investimentos 
de infraestrutura para logística portuária e de transporte, na expectativa do desenvolvimento futuro do agronegócio [...] (ARAÚJO, 2008, p. 46). A agricultura mecanizada pode crescer tanto em direção às áreas devolutas do polo de Santarém, após a exaustão de seus recursos madeireiros, quanto para os municípios de terras planas e férteis na Calha Norte do Amazonas (ARAÚJO, 2008, p. 63).

Figura 2: Desempenho dos estados produtores de soja nas regiões Norte e Nordeste, de 1979-2011 (em 1.000t).

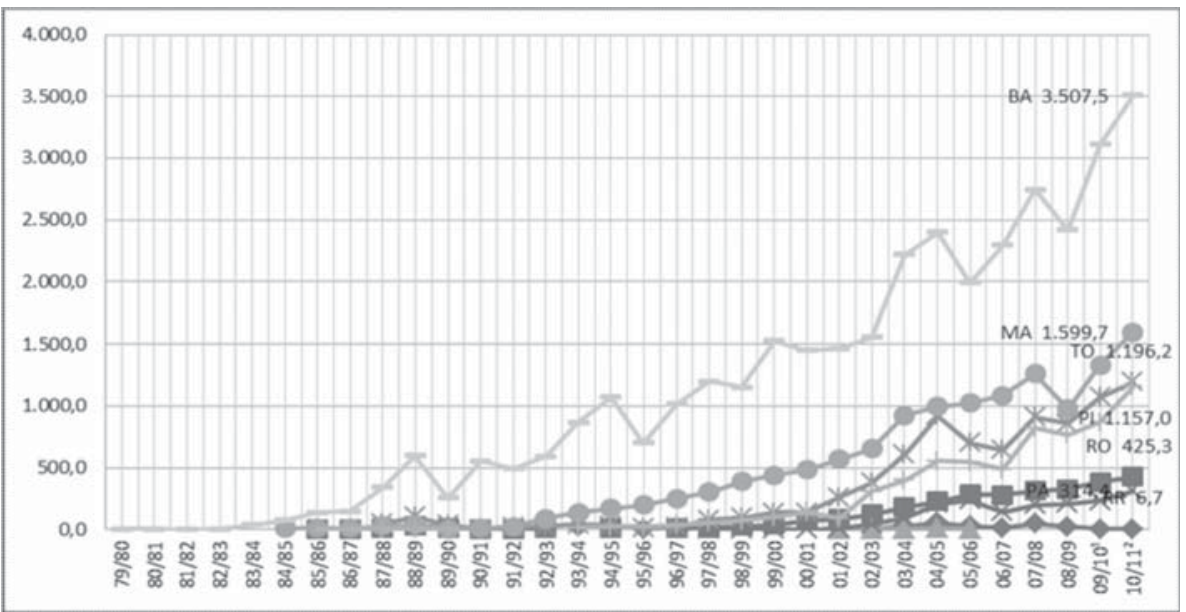

Fonte: CONAB, 2011.

O biólogo pesquisador do INPA-AM, Philip Martin Fearnside (2005), corrobora o diagnóstico do avanço do cultivo da soja sobre a Amazônia. Associa a crescente demanda mundial - a qual denomina causa inicial - ao desmatamento na fronteira, o que denomina: "efeito de arrasto". Afirma: "A soja pode estimular o desmatamento em fazendas amazônicas, mesmo que floresta não seja derrubada para seu cultivo" [...] (FEARNSIDE. 2005, p. 284). Muitos dos efeitos dos projetos de infraestrutura vêm do que os planejadores brasileiros chamam do "efeito de arrasto", ou seja, a estimulação de investimento privado como resultado de uma despesa pública em um projeto.

O "efeito de arrasto" escapa completamente do atual Relatório de Impactos sobre o Meio Ambiente (RIMA) e o processo de licenciamento de projetos. Os custos incluem a perda de biodiversidade, quando são convertidos ecossistemas naturais em campos de soja, impactos severos de alguns dos sistemas de transporte, erosão do solo e efeitos de substâncias químicas agrícolas sobre o meio ambiente e sobre a saúde humana, a expulsão de populações que antes habitavam as áreas usadas para soja [...] (FEARNSIDE, 2005, p. 287). 
Fearnside utiliza as categorias de espaço-tempo para analisar e fazer previsão quanto à expansão daquele cultivo no período compreendido entre 1970 a 1998 apresentadas no mapa ilustrativo (Figura 3a-c).

Figura 3a-c. Avanço da soja ao longo do período 1970-1996 no Brasil.

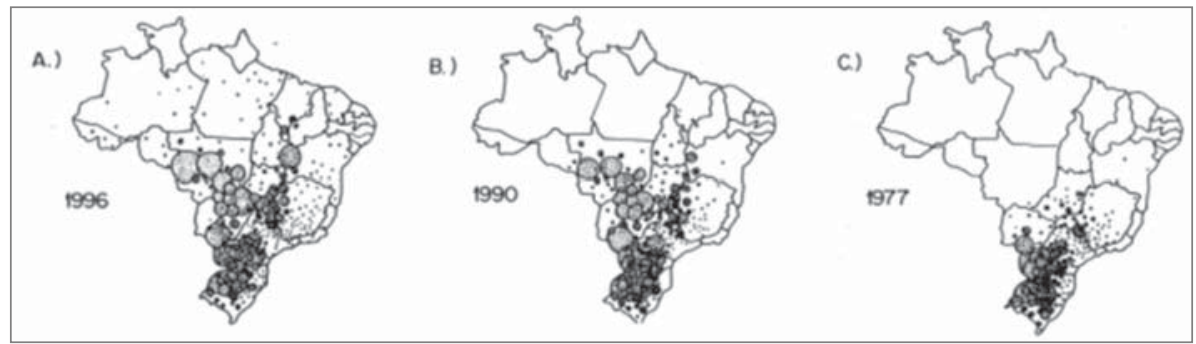

Fonte: Fearnside (2005, p. 289).

Com base nas simulações da Figura 3a-c, é plausível a hipótese que a sojicultora esteja avançando a passos largos em direção a Amazônia Oriental. O próprio autor registra que a área total do cultivo de soja parou de crescer em 1998, em termos nacionais, mas alerta que houve um deslocamento de região central do país para o norte. Na verdade, nesse ano inicia-se o plantio no estado do Pará, sendo irregular até 2001/2002, causando, nesse período, um impacto marginal no crescimento da área plantada dessa oleaginosa, em termos regionais. Apenas nos estados de Roraima e Tocantins, as áreas cultivadas mais que dobraram no período 1997/1998 a 2011/2012, aproveitando os potenciais dos seus cerrados. Isto nos conduz a pensar que a marcha da soja sobre a Amazônia tem efeitos espaciais heterogêneos ano a ano, não permitindo uma análise espacial com intervalos de cinco ou dez anos.

Em relação aos impactos ambientais e sociais, Fearnside (2005) destaca que:

Um impacto mais óbvio é a perda de ecossistemas naturais convertidos em soja. No entanto, poucos sojicultores cortaram floresta para a soja; ao invés disso, eles compram terras já desmatadas dos agricultores pequenos, que se movimentam para áreas de fronteira e desmatarão mais (FEARNSIDE, 2005, p. 293) [...]. Agrotóxicos usados para combater doenças, insetos e ervas daninha no cultivo da soja podem ter impactos no ambiente, como também nas pessoas expostas a eles [...]. Durante o período de vazante encolhem ou secam os lagos da várzea, concentrando os peixes que são facilmente capturados. Se as terras circunvizinhas estiverem plantadas com soja, pode-se esperar que as altas doses de agrotóxicos usadas nessa cultura concentrar-se-ão nos lagos e nos peixes (FEARNSIDE, 2005, p. 294). 
Os gastos em infraestrutura de transporte (hidrovias, rodovias e ferrovias) para o escoamento da safra colhida, tem sido alvo de crítica do pesquisador, quando analisado sob a ótica de atração de novos empreendimentos e as possíveis consequências ao meio ambiente. Pode-se tomar como exemplo o crescimento populacional abrupto e a ocupação urbana desordenada no entorno dos municípios que experimentam a invasão da soja.

Nepstad et al. (2008), de forma mais moderada, relaciona a expansão do desmatamento na região amazônica à expansão da soja no Mato Grosso, devido à descomunal valorização das terras mais aptas ao seu cultivo. Dessa forma, pecuaristas vendem suas propriedades a sojicultores para comprar terras baratas mais ao norte, o que permitiu aumentar os rebanhos (NEPSTAD, 2008, p. 49). Afirma:

A maior parte do aumento no desmatamento pode ser evidenciada pela expansão do rebanho bovino na região (KAIMOWITZ et al., 2004), entretanto as indústrias de soja e de carne não funcionam independentes uma da outra. O decréscimo de 30\% no preço da soja de 2003 a 2005, todavia, e o aumento nos custos das exportações brasileiras, associado ao aumento de $25 \%$ ao aumento na força do Real, foram fatores importantes na desaceleração, tanto da expansão da agroindústria quanto da pecuária na região, como o refletido nas estimativas de desmatamento para 2005. A maioria dos produtores de soja não foi capaz de saldar o crédito concedido pelos distribuidores de sementes e produtos agroquímicos e pelas instituições financeiras, as quais privaram a região do capital usado em anos anteriores para adquirir novas terras e converter a floresta em pasto e plantações (NEPSTAD, 2008, p. 50).

Este movimento intenso de comercialização de terras também foi identificado por Campos (2007), dentro do próprio setor sojicultor, conforme demonstra a seguir:

Embora seja condição sine qua para empreendedorismo da soja, a terra não é um bem que possa ser reproduzido, como um bem de capital qualquer. Pelo contrário, é um bem escasso e encontra-se sob propriedade privada. O processo de concentração da terra entre os mais bem sucedidos empresarialmente pressupõe a sua outra face, ou seja, a existência de agricultores não tão bem sucedidos. Estes venderam suas terras, muitas vezes em busca de novas terras mais baratas, como fizeram anteriormente no Rio Grande do Sul (CAMPOS, 2007, p. 241).

A consequência direta do exposto acima é que do ponto de vista técnico e econômico persistem pressões para uma maior concentração de terras e da produção, num número cada vez menor de produtores na região. As crises, como a vivenciada pelos produtores de soja nas safras 2004/2005 e 2005/2006, 
constituem o momento histórico da concorrência dos sojicultores pelo acesso à terra em regiões há muito incorporadas, onde a ruína de uns se configura na oportunidade de crescimento dos concorrentes.

Quanto aos impactos ambientais e sociais causados pela expansão da soja, Nepstad et al. (2008) destaca inicialmente o aumento na taxa de desmatamento e, consequentemente, o crescimento nos níveis de emissão de gases de efeito estufa na atmosfera, além do risco de desaparecimento de regiões de ecossistema vulnerável ao desmate, estressamento de corpos hídricos de algumas bacias próximas às áreas de cultivo e/ou de pecuária, alterando o ciclo de chuvas da região, ameaçando o bioma amazônico. Quanto aos efeitos antrópicos, estes recaem sobre os pequenos produtores e comunidades indígenas, desalojando-os para outras áreas, aumentando a especulação sobre o preço das terras, juntamente com a violência no campo. Entretanto, o autor visualiza possibilidades de mitigação dos impactos negativos do cultivo da soja (NEPSTAD et al., 2008), via práticas mais saudáveis, tais como: uso de agrotóxicos certificados, emprego de plantio direto, cumprimento da legislação ambiental e trabalhista, dentre outras. Esta tendência inicia-se na obtenção dos empréstimos por parte dos cultivadores, pois os agentes financeiros externos condicionam o financiamento à adoção de práticas de manejo ecologicamente corretas, dado o interesse dos consumidores finais em não consumir grãos cuja produção não tenha implicado em desmatamento.

Campos (2007) associa a continuidade da produção de soja nas áreas tradicionais de cerrado à conservação do bioma amazônico, confrontandoas negativamente com o velho binômio madeireira/pecuária, tão comum na história econômica da fronteira agrícola em outras regiões do país, mesmo antes da expansão do cultivo da soja no Brasil, e que se repete na Amazônia, sendo este o verdadeiro motor do desmatamento (CAMPOS, 2007, p. 252). Este autor considera a preservação da floresta amazônica como imprescindível para a manutenção da sojicultora no centro-oeste, pois

[...] estudos climáticos apontam para os riscos potenciais que mudanças climáticas causadas pelo desmatamento na floresta amazônica podem acarretar a assim chamada Zona de Convergência do Atlântico Sul. Esta advém do encontro das frentes oriundas do sul com o ar quente e úmido vindo da região amazônica, do qual a estação chuvosa no cerrado do Centro-Oeste é tão dependente. Mais do que quaisquer outros, os produtores de soja do Centro-Oeste seriam os primeiros a ser fortemente atingidos pelas mudanças no clima do Centro-Oeste, pois dependem fortemente da conservação dos ecossistemas da região amazônica para continuarem em sua atividade" (CAMPOS, 2007, p. 252). 
Sem a cobertura florestal, que retêm a água das chuvas e a devolve à atmosfera por meio da evapotranspiração, a umidade que penetra na calha amazônica retornaria aos oceanos, escoando pela malha hidroviária. A consequência direta seria uma forte perturbação para baixo no regime de chuvas do Centro-Oeste.

De uma forma geral, o debate sobre a expansão do cultivo da soja na Amazônia gira mais em torno de conjecturas sobre seus eventuais efeitos negativos, sem, no entanto, fornecer uma base empírica consistente sobre o fato. Do ponto de vista prático, atendendo o objetivo de coibir o avanço do desmatamento, esta prática acobertar os reais responsáveis pelo avanço do desmatamento.

Prever uma possível expansão do cultivo da soja na região amazônica implica a determinação prévia dos fatores que viabilizaram a expansão do cultivo da soja em outras regiões do país. Num segundo momento, deve-se verificar a presença ou não destes na região amazônica, evitando-se tentações das generalizantes em face da heterogeneidade regional. Faz-se necessário o emprego de instrumentos de econometria espacial, correlacionado produção a fatores naturais e econômicos.

\section{METODOLOGIA}

A Econometria Espacial é o campo onde Análise Espacial e a Econometria se encontram. Em geral, a Econometria difere da Estatística, pois a primeira busca construir modelos teóricos, cujos parâmetros são estimados. A Econometria Espacial é um refinamento dessa estimação, onde um modelo teórico envolve interações entre diferentes agentes ou onde os dados não são verdadeiramente independentes. Para Anselin (2006), a Econometria Espacial é um subcampo da Econometria, que lida com o tratamento da interação espacial (spatial autocorrelation) com a estrutura espacial (spatial heterogeneity), nos modelos de regressão que utilizam dados em corte transversal (cross section) ou tabelados (panel data). O interesse sobre a localização e a interação espacial tem recebido grande importância, não só na aplicação de métodos, mas também na teoria econométrica. No passado, modelos que incorporavam “espaço” (ou Geografia) e, portanto, aplicações de Econometria Espacial, eram utilizados em estudos especializados na área da economia regional e urbana. As aplicações empíricas utilizando Econometria Espacial têm crescido nos últimos anos, em diversas áreas da economia, entre outros estudos de análise de demanda (CASE, 1991), de economia internacional (ATEN, 1996), de economia do trabalho (TOPA, 1996), de economia do setor público 
(CASE; ROSEN; HINES, 1993) e de economia ambiental e agrícola (BENIRRSCHKA; BINKLEY, 1994; MURDOCH; SANDLER; SARGENT, 1997; NELSON; HELLESRSTEIN, 1997; BELL; BOCKSTAEL, 1999).

Deste modo, o modelo se comporta identificando autocorrelação espacial, podendo esses efeitos serem estimados utilizando a análise de regressão da Econometria Espacial (Spatial Regression Analysis).

Podemos usar os conceitos de Paelinck-Klaassen (1979) e de Luc Anselin (1988; 2006) para definir a Econometria Espacial (Spatial Econometrics). PaelinckKlaassen (1979) preconizam a existência de uma regra de interdependência espacial entre os agentes. Esses agentes desenvolvem relações espacialmente assimétricas, devido à importância dos fatores em outros espaços. Ocorrendo uma interação, provoca-se uma diferenciação no espaço ex post e ex ante. As interações podem ser de natureza entre indivíduos ou sociais ou ainda de redes. Anselin (1988) define a Econometria Espacial como "o conjunto de técnicas que trata as peculiaridades causadas pelo espaço na análise estatística nos modelos de estudos regionais". Segundo este autor, essa definição é bastante restritiva, pois, num contexto de dependência espacial (spatial dependence) de dados de corte transversal (cross section), a estrutura de correlação ou covariância entre variáveis aleatórias e diferentes locações é obtida a partir de um ordenamento específico, determinado pela posição relativa (distância, por exemplo) das observações no espaço geográfico (ou em uma rede). Anselin (2006) reapresenta o conceito de Econometria Espacial, e a define como "ramo do método econométrico que trata os aspectos espaciais nas observações do tipo amostral (cross section) e de espaço-tempo".

\section{ECONOMETRIA ESPACIAL E CIÊNCIAS SOCIAIS}

No artigo "Espacialidade Integrada a Ciência Social", de Goodchild et al. (2000), os autores ressaltam o crescente interesse da pesquisa em ciências sociais utilizando os conceitos de espaço e tempo como ferramenta de análise nas últimas duas décadas. Este fato está relacionado à noção geral do conceito de compressão espaço-tempo (space-time compression). Em outras palavras, o uso de tecnologias como a do microchip, canais de televisão por satélite e transporte de pessoas e cargas em dimensões transoceânicas, aliado ao grande fluxo migratório ao redor do globo, todos estes fatores têm afetado profundamente a organização espacial sob a ótica social, econômica, política e cultural. As categorias espaço e tempo têm sido utilizadas de forma privilegiada pela Geografia e de pouca 
utilidade para as Ciências Sociais. Isto tem mudado. Recentemente, cientistas sociais têm procurado novas tecnologias e metodologias de análise espacial (GPS - global positioning system, sensoriamento remoto e estatística espacial), usando-as de forma efetiva nos diversos trabalhos científicos. Dessa forma, os autores concordam que é possível ocorrer uma completa integração da perspectiva espacial no campo teórico e metodológico das Ciências Sociais.

Os autores acreditam que um esforço concentrado no avanço e disseminação das ferramentas que a Geografia se utiliza e nos conceitos como análise espacial, sistemas de informação geográfica e geolivrarias, integra os temas que atravessam as fronteiras da disciplinaridade tradicional, possibilitando o desenvolvimento de uma ampla visão espacial orientada no futuro da pesquisa das Ciências Sociais.

\subsection{Espaço no paradigma atual}

Para a nova Geografia Econômica, local e espaço formam a base da ciência regional, juntamente com o uso de ferramentas modernas de análise matemática. São os princípios teóricos do comércio e do desenvolvimento econômico. Os modelos mostram que economias de escala com retornos crescentes, dependência e competição imperfeita induzem várias formas de externalidades espaciais, economias de aglomeração e excedentes, cujo traço espacial requer uma abordagem de econometria espacial num trabalho empírico. $\mathrm{Na}$ Sociologia, é dada uma renovada atenção à perspectiva ecológica, iniciada pela Escola de Chicago, na década de 1920, quando um crescente número de estudos tem utilizado mapas computadorizados e técnicas de análise espacial. Esses esforços acompanham as estruturas teóricas que relacionam o comportamento individual para o contexto geográfico nas investigações empíricas sobre capital social, senso de pertencimento daquela comunidade e efeitos da vizinhança. Na Ciência Política, especialmente no estudo de relações internacionais, uma perspectiva espacial está cada vez mais em uso na teoria, como também na abordagem empírica, sugerindo a formação de novos geopolíticos.

\subsection{Estudos urbanos}

Existe um renovado interesse na importância das interações sociais que contribuem para o fortalecimento de economias regionais, instituições e culturas. Cada interação é frequentemente vista como puramente de natureza econômica. Mas o simbólico significado de localização pode também ter efeitos econômicos, 
como é evidenciado no caso de concentração de indústrias numa cidade, por exemplo. Análise usando o Geographic Information System (GIS) tem sido aplicada para examinar as relações entre etnicidade, espaço e a localização da produção. Essa interação pode ser apresentada pela metodologia de estatística e econometria espacial.

\subsection{Negócios e redes sociais}

Redes Sociais, em geral, são conceituadas fundamentalmente em termos de desagregação espacial, e muitos dos cientistas sociais estão analisando aspectos espaciais de redes, por exemplo, identificando a rota de migrações transnacionais ou identificando populações que apresentam alto risco de ocorrência de tragédias. Paralelamente, trabalhos sobre redes sociais têm chamado a atenção da Economia para introdução de agentes e noções relacionadas à interação estratégica. Redes de negócios são, da mesma forma, foco de uma análise espacial extensiva.

\subsection{Desigualdade social e econômica}

A distribuição espacial da desigualdade tem chamado a atenção de antropólogos, sociólogos e cientistas políticos. A existência da concentração de pobreza regional e interurbana, frequentemente próxima de atividades que geram riqueza, encaminha-nos para uma análise espacial. Por exemplo, cidades como Nova Iorque, Londres e Tóquio não apenas servem como centros financeiros globais e de comando de corporações, mas, por alguma razão, também criaram concentrações de minorias e, frequentemente, em grande parte, de imigrantes, populações que fornecem serviços de suporte ao centro financeiro.

4.5 Meio ambiente e mudança climática

Sensoriamento remoto, GIS e Econometria Espacial têm sido efetivamente usados para analisar as relações entre atividades humanas e mudança ambiental local, em particular em áreas de desflorestamento e mudança no padrão do uso da terra. A sustentabilidade ambiental tem recebido um tratamento de dimensão espacial pelos pesquisadores interdisciplinares das ciências sociais, de forma substancial, metodológica e teórica.

Os arqueólogos estão na vanguarda dos cientistas sociais, incorporando sofisticados métodos de análise espacial, por exemplo, comparando a arqueologia pré-histórica e contemporânea com fenômenos sociais. 
A relação entre atividades humanas e mudança climática global permanece apenas parcialmente articulada. Cientistas que estudam o planeta Terra têm desenvolvido modelos robustos que explicam e preveem que mudanças estão ocorrendo apenas sobre a base física. Por exemplo, o Modelo do Sistema de Pesquisa Climática do Centro Nacional para Atmosfera ajusta interações complexas de todos os aspectos do sistema climático: atmosfera, oceano, geleira, hidrosfera, biosfera, ecossistema terrestre e processos na superfície terrestre. Cada modelo leva em consideração as variações climáticas regionais, que ocorrem devido às ações humanas, como diferenças regionais no crescimento populacional, migrações, industrialização e urbanização.

\section{VISUALIZAÇÃO ESPACIAL DOS MUNICÍPIOS BRASILEIROS PRODUTORES DA SOJA}

Dos 5.564 municípios brasileiros, 1.826 , ou seja, 33\% produziram soja no ano de 2007. O recorde de produção pertence ao município de Sorriso, no estado do Mato Grosso, com 1.662.666 toneladas, seguido por Sapezal, também no Mato Grosso, com pouco mais de 1.000 .000 toneladas. Apenas 198 municípios produziram acima de 50.000 toneladas/ano, representando pouco mais de $10 \%$ do total dos municípios produtores, os quais foram submetidos a uma análise de econometria espacial. Para identificação espacial desses municípios, foi gerado um mapa temático, plotados nas Figuras 4 e 5. Este recorte metodológico se justifica, pois os municípios que produzem abaixo de 50.000 toneladas de soja geralmente orbitam os maiores produtores, dificultando a identificação de onde começa e termina um agrupamento relevante. Registre-se que o mapa temático apenas identifica os municípios e não a área plantada. 
Figura 4: Distribuição espacial dos municípios produtores de soja no Brasil em 2007.

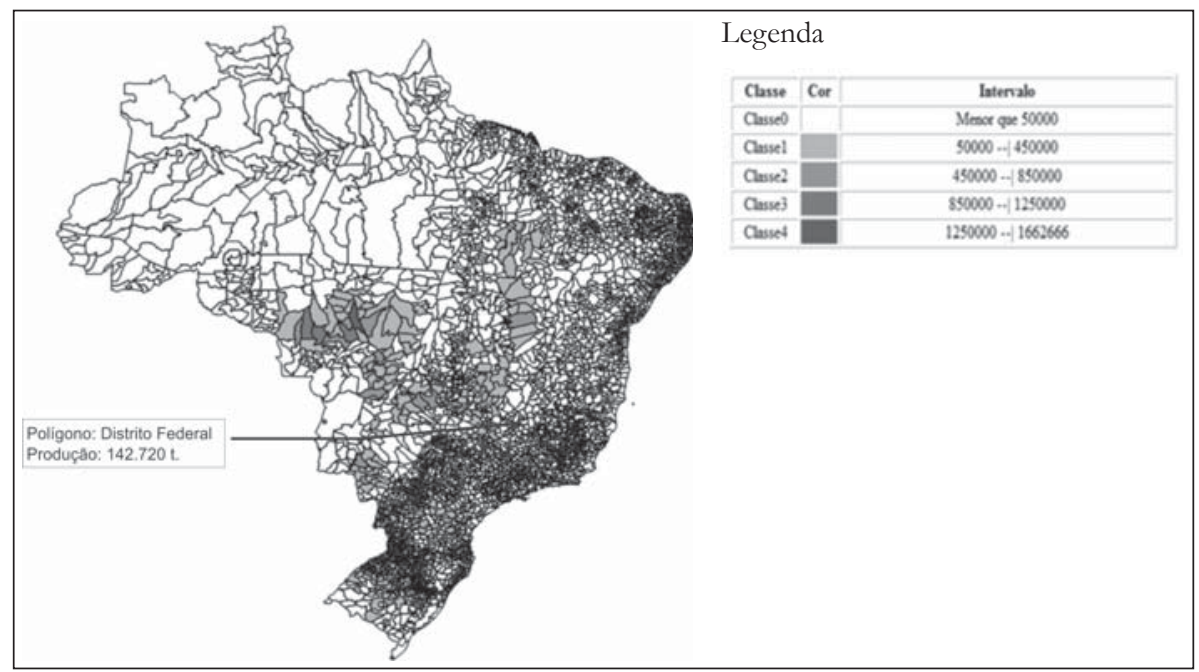

Fonte: IPEA.

Figura 5: Corte ampliado dos municípios produtores de soja no Brasil - 2007.

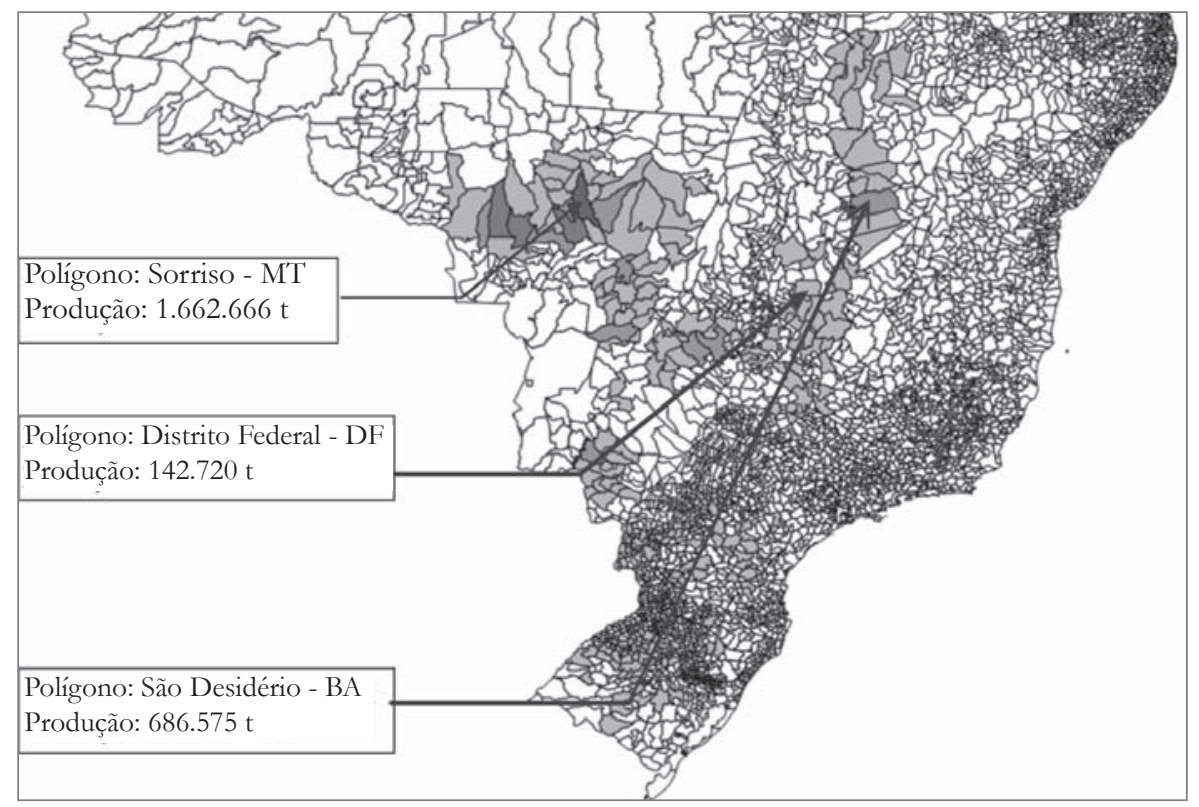

Fonte: IPEA. 
Constata-se visualmente a existência de uma concentração espacial da produção de soja em pelo menos dois grandes grupos. O primeiro agrupamento parte do sudoeste do Mato Grosso do Sul, passa pelo oeste e meio oeste dos estados de São Paulo e Paraná, estendendo-se à direita da região de relevo acidentado do oeste de Santa Catarina e noroeste gaúcho, chegando aos limites do Rio Grande do Sul com o Uruguai. Configura a primeira grande fase de expansão da soja no Brasil, entre 1960 e 1980, a partir do Rio Grande do Sul.

O segundo agrupamento, de formação mais recente, é um imenso cluster que parte do sul de Rondônia, corta os estados de Mato Grosso e Goiás, prolongando-se ao sul para o noroeste de Minas Gerais, para, enfim, chegar aos cerrados do Sul do Maranhão e do Piauí e da fronteira oeste da Bahia. A forma deste agrupamento contraria a hipótese defendida por alguns pesquisadores de que a soja estaria avançando sobre a Amazônia. Na Figura 5, um corte ampliado do mapa temático anterior, pode-se verificar que a área de expansão recente da soja no Brasil é formada por áreas com uma concentração maior na produção, intercaladas por áreas com menor ou ausência de produção de soja. O avanço não apresenta o formato de um arco, comprimindo cada vez mais em direção à floresta tropical úmida (tese sucuri), mas estende-se diagonalmente ao longo das áreas de cerrados dos estados do Maranhão, Piauí, Tocantins e Bahia (MAPITOBA). A distribuição espacial da produção nos agrupamentos (clusters) não é de forma alguma homogênea, tampouco concêntrica, prenunciando que a distribuição espacial do cultivo da soja atende a vários fatores, os quais, por sua vez, estão distribuídos regionalmente - espaço igualmente de forma não homogênea.

\section{CONDICIONANTES AO CULTIVO DA SOJA}

Segundo Paulo Roberto Geleranie (engenheiro agrônomo da EMBRAPA), a soja

[...] é uma cultura que recicla nutrientes, melhora a condição do solo, tem uma relação carbono/nitrogênio bastante baixa, ou seja, devolve ao solo o nitrogênio com muita facilidade, sem contar o nitrogênio que ela fixa via bactéria.... ela suporta alguns anos de monocultura, ou seja, você pode plantar em anos seguidos que ela mantém a produtividade, o que não acontece com algumas outras culturas. ${ }^{1}$

MPEG. Caderno “Idéias e Debates", número 8, p. 39, maio de 2004, p. 39. 
Apesar das vantagens mencionadas, o plantio da soja apresenta quatro grandes fatores condicionantes: solo e relevo; exigências climáticas; infraestrutura e logística; e financiamento.

\subsection{Solo e relevo}

Os solos, além de permitirem a correção do ph, devem ser profundos e planos, permitindo a mecanização de grande porte, favorecendo maior rendimento nas operações de preparo do solo, tratos culturais e colheita. O manejo e a rotação de culturas resultam na substituição quase total da semeadura convencional pela direta (plantio direto), com reflexos positivos na sustentabilidade dos sistemas produtivos.

\subsection{Exigências climáticas: água e temperatura}

Adisponibilidadedeáguaéimportante em doisperíodos de desenvolvimento da soja: 1. Germinação-emergência: nessa fase, tanto o excesso quanto o déficit de água são prejudiciais à obtenção de uma boa uniformidade na população de plantas. Para assegurar uma boa germinação, a semente necessita absorver, no mínimo, $50 \%$ de seu peso em água. Isso é possível, caso o conteúdo de água no solo não exceda a $85 \%$ do total máximo de água disponível e nem ser inferior a $50 \%$. 2. Floração-enchimento de grãos: a necessidade de água na cultura da soja vai aumentando com o desenvolvimento da planta, atingindo o máximo nesse período e depois decrescendo. Déficits hídricos expressivos durante a floração e o enchimento de grãos alteram as características fisiológicas na planta, como o fechamento estomático e o enrolamento de folhas, que consequentemente causam a queda prematura de folhas e de flores, abortamento de vagens e, por fim, redução da produção. A regularidade das chuvas no período da germinação e floração é imprescindível para o bom desenvolvimento da planta. No entanto, o excesso de chuva no período da colheita possibilita o aparecimento de alta porcentagem de grãos ardidos, mofados e $\backslash$ ou germinados, reduzindo a qualidade e a produção.

Quanto à temperatura, a soja se adapta melhor a temperaturas do ar próximas a $30^{\circ} \mathrm{C}$, ideais para o seu crescimento e desenvolvimento. A sensibilidade ao fotoperíodo é uma característica geneticamente selecionada para cada cultivar, regulando o momento do florescimento. A soja é considerada planta de dias curtos. Em função disso, a faixa de adaptabilidade de cada cultivar varia à medida que se desloca em direção ao norte ou ao sul. Entretanto, cultivares que 
apresentam a característica periodo juvenil longo possuem adaptabilidade mais ampla, possibilitando sua utilização em faixas mais abrangentes de latitudes (locais) e de épocas de semeadura. Assim, jogar com épocas de plantio e variedades de ciclo mais longo ou curto permite uma perfeita adequação das características da cultivar com a latitude e o regime de chuvas de cada região.

\subsection{Infraestrutura e logística}

Devido aos elevados custos de produção, os custos de escoamento da safra afetam sensivelmente a rentabilidade do cultivo da soja. Tal fato explica porque áreas com condições edafoclimáticas propícias, como no entorno de Sorriso, no Mato Grosso, só tenham experimentado uma maior expansão do cultivo da soja após a sua interligação aos principais corredores de exportação brasileiros. Estes custos podem ser fortemente minorados via investimentos em infraestrutura de transportes multimodais.

\subsection{Financiamento da produção}

Dadas as exigências da cultura e aos elevados custos de produção, associados a uma escala ótima de produção elevada e crescente (acima dos $1000 \mathrm{ha}$ ), os produtores de soja dependem sobremaneira de financiamentos para fazerem face aos investimentos e custeio. Suas necessidades financeiras em muito extrapolam os limites máximos de financiamento do crédito agrícola oficial por produtor ( $\mathrm{R} \$ 500.000,00$ para a safra 2011/2012). Desta forma, o financiamento da produção geralmente é fruto da venda antecipada da safra para as assim chamadas "tradings". As grandes multinacionais que dominam o comércio internacional de grãos desfrutam de um elevado nível de controle sobre a atividade. Se, por um lado este fato lhes permite repassar aos produtores diretos os riscos inerentes à atividade, por outro, tornam-lhes vulneráveis a pressões ecológicas nacionais e internacionais.

\section{INCERTEZAS DA SOJICULTURA}

Dados os elevados investimentos de longo prazo e altos gastos de custeio associados ao cultivo da soja, esta atividade é altamente suscetível aos riscos inerentes ao setor. Falta ou excesso de chuva, surgimento de doenças e pragas etc., podem acarretar prejuízos ao empresário agrícola. Seguindo à risca o pacote 
tecnológico da soja adaptado às condições brasileiras, o potencial médio de produtividade da soja gira em torno de $3.000 \mathrm{~kg} / \mathrm{ha}$. Qualquer condição adversa implica em redução da produtividade e queda nos lucros esperados, podendo inclusive causar prejuízos que, por vezes, levam os produtores menores a venderem as terras como forma de quitar dívidas contraídas. Só em situações excepcionais de preços, estes compensariam investimentos em áreas de maior risco, menos aptas à sojicultura.

A época de semeadura é um dos fatores que mais influencia o rendimento da lavoura da soja. Como se trata de uma espécie termo e fotossensível, está sujeita a alterações fisiológicas e morfológicas, quando as suas exigências não são atendidas. Nesse período, a exposição da soja à variação dos fatores climáticos limitantes pode afetar o porte, o ciclo, o rendimento das plantas e aumentar as perdas na colheita, no caso de ocorrência de uma adversidade climática. $O$ elevado risco é a variável que restringe a expansão do cultivo da soja àquelas áreas que reúnem as condições ideais de solo e clima associados a modais de transporte e financiamento da produção.

\section{CONCLUSÃO}

No presente artigo buscou-se elucidar a questão se existiriam limites à expansão do cultivo da soja na Amazônia, a partir do uso da lupa da Econometria Espacial sobre o cultivo dessa oleaginosa em outras regiões do país.

$\mathrm{O}$ argumento de aceitação geral, de que na Amazônia a expansão do cultivo da soja teria a mesma dinâmica encontrada no Centro-Oeste brasileiro, a partir de investimentos em infraestrutura de transporte - o chamado "efeito arrasto" não se sustenta. O caso de Rondônia é emblemático. A criação de um sofisticado modal de transporte fluvial pelo rio Madeira até o porto de Itacoatiara, em muito barateou o custo de transporte da soja cultivada no oeste de Mato Grosso, sem, no entanto, transformar Rondônia em um imenso monocultivo de soja. A área ocupada pela cultura se reduziu aos cerradões planos do sul do estado, no entorno de Vilhena. A cultura da soja, por seus elevados custos, além se ser uma atividade de alto risco, está sujeita a fortes flutuações nos níveis de pré. Da forma com que o mercado está estruturado, dominado por grandes tradings, este risco recai fortemente sobre os produtores diretos. A configuração extremamente heterogênea do segundo cluster da soja no Brasil, indica claramente que a ocorrência de enormes monocultivos de soja está associada à ocorrência conjunta de quatro condições ideais, a saber: solos profundos e planos; regime 
hídrico regular; infraestrutura de transporte; e financiamento. Na Amazônia, esta configuração se restringe às parcas áreas de cerrado. $\mathrm{O}$ binômio madeireirapecuária segue sendo o grande vilão a ser controlado.

\section{REFERÊNCIAS}

ANSELIN, L. Spatial Econometrics: methods and models. Dordrecht; Boston; London: Kluwer Academic Publishers, 1988.

Spatial Econometrics. Bruton Center. Dallas: University of Texas at Dallas, 1999.

Spatial Econometrics. In: MILLS, T.; PATTERSON, K. (Eds.). Palgrave handbook of Econometrics econometric theory. Basingstoke: Palgrave Macmillan, 2006. v. 1.

. Thirty years of spatial econometrics. Papers in Regional Science, v. 89, n. 1, p.3-25, 2010.

ARAÚJO, R. et al. Estado e Sociedade na BR-163: desmatamento, conflitos e processos de ordenamento territorial. In: CASTRO, E. (Org.). Sociedade, território e conflitos: BR-163 em questão. Belém: NAEA, 2008. p. 13-83.

BAER, W.; MUELLER, C. C. Aspectos ambientais do desenvolvimento do Brasil. In: BAER, W. A Economia Brasileira. São Paulo: NOBEL, 2009. p. 420-455.

CAMPOS, I. Arranjo Produtivo Local da Soja - Sorriso - MT. In: CAMPOS, I. (Org.). Plano de Desenvolvimento Sustentável da Amazônia Legal - Estudos de Aglomerações - PDSA 2005-2008. Belém: ADA;UFPA, 2007. p. 235-253.

FEARNSIDE, P. M. O cultivo da soja como ameaça para o meio ambiente na Amazônia Brasileira. In: VIEIRA, I.; FORLINE, L.; MURRIETA, I (Orgs.). Amazônia além dos $\mathbf{5 0 0}$ anos. Belém: Museu Paraense Emílio Goeldi, 2005. p. 281-324.

FILGUEIRAS, G. C. et al. Análise do mercado e da concentração espacial da cadeia produtiva da soja na Amazônia. Belém: Banco da Amazônia, 2007. (Estudos Setoriais, 4).

GOODCHILD, M. F.; ANSELIN, L.; APPELBAUM, R. P.; HARTHORN, B. H. Toward Spatially Integrated Social Scene. International Regional Science Review, v. 23, n.2, p. 139-159, 2000. 
LeSAGE, J.; PACE, R. K. Introduction to Spatial Econometrics. [s.l.]: CRC Press, 2009.

LIRA, S. R. B. de et al. Desigualdade e heterogeneidade no desenvolvimento da Amazônia no século XXI. Revista Nova Economia, Belo Horizonte, v. 19, n. 1, p. 153-184, 2009.

KAIMOWITZ, D.; MERTENS, B.; WUNDER, S; PACHECO, P. Hamburger Connection Fuels Amazon Destruction. Bogor: Center for International Forestry Research, 2004. Disponível em: <http://www.cifor.cgiar.org>.

MARQUES, R. W. da C.; REZENDE, G. C.; BRANDÃO, A. S. P. Crescimento Agrícola no período 1999/2004. Explosão da área plantada com soja e meio ambiente no Brasil. Rio de Janeiro: IPEA, 2005. (Texto para Discussão n. 1062).

NEPSTAD, D. C.; STICKLER, C.M.; ALMEIDA, O.T. A globalização das indústrias de soja e de gado na Amazônia: oportunidades para conservação. In: RIVERO, S.; JAYME JÚNIOR, F. G. (Orgs.). As Amazônias do Século XXI. Belém: EDUFPA, 2008. p. 41-66.

PAELINCK, J.; KLAASSEN, L. Spatial Econometics. FarnBorough: Saxon House, 1979.

RINDFUSS, R. R.; STERN, P. C. Linking Remote Sensing and Social Science: the need and the Challenges. In: LIVERMAN, D.; MORAN, E.F.; RINDFUSS, R.R.; STERN, P.C. (Eds.). People and pixels. Washigton: National Academic Press, 1998.

SALAZAR, L. F. Desmatamento, mudanças climáticas e a hipótese de "savanização" da Amazônia. In: BUENAFUENTE, S. (Org.). Amazônia: dinâmica do carbono e impactos socioeconômicos e ambientais. Boa Vista: UFRR, 2010. p. 17-26.

THÉRY, H. Dinâmicas geográficas da soja no Brasil. In: Terceiro Atelier de Análise Prospectiva: a dinâmica da soja e seus impactos no futuro da Amazônia. Brasília, DF: [s.n.], 1999. Disponível em: < http://www.bcdam.gov.br>. Acesso em: 5 abr. 2012.

TYSZLER, M. Econometria Espacial: discutindo medidas para a matriz de ponderação espacial. 2006. 155f. Dissertação (Mestrado em Administração Pública e Governo) - Fundação Getúlio Vargas, São Paulo, 2006.

VIEIRA, I. C. G. (Ed.). Caderno “Ideias e Debates”, n. 8, maio. Belém: Museu Paraense Emílio Goeldi, 2004. 